\title{
Considerações sobre o comportamento de competidores de judô e jiu-jítsu para rápida perda de peso pré-competição
}

\section{Considerations about the behavior of judo and jiu-jitsu competitors for fast weight loss before competition}

\author{
Camila Kelly de Sena Souza' \\ Edeli Simioni de Abreu' \\ 1 Universidade Presbiteriana Mackenzie, Curso de \\ Nutrição. São Paulo-SP, Brasil. \\ Correspondência / Correspondence \\ Edeli Simioni de Abreu \\ E-mail:edelisabreu@gmail.com
}

\section{Resumo}

O judô e o jiu-jítsu são modalidades de luta que têm base em técnicas de defesa pessoal e possuem código moral específico. Nas modalidades de combate, os competidores são classificados levando-se em consideração a idade e o peso, além da graduação técnica dentre a modalidade praticada. Em virtude dessa classificação, comumente percebe-se competidores que buscam manipular essas variáveis. A manobra mais utilizada e mais citada pelos atletas é a redução do peso corporal em períodos que antecedem os campeonatos, a fim de enfrentar adversários menores e mais leves. Neste trabalho, objetivou-se investigar os métodos para perda de peso usados por competidores de judô e jiu-jítsu e o discurso para justificar a conduta. Participaram do estudo competidores do sexo masculino, de diversas graduações de judô e jiu-jítsu. As informações foram coletadas com aplicação de um questionário com perguntas específicas abertas e fechadas sobre alimentação, treino e competições, além de sobre medidas antropométricas. A amostra foi composta por seis atletas do jiujítsu e quatro judocas, com idade média de 23,1 anos e todos com tempo total de treino superior a 12 meses. Apenas um atleta afirmou não ter familiaridade com quaisquer técnicas para rápida perda de peso; cinco declararam realizar alguma manobra para manipulação do peso e quatro atletas disseram que apenas conheciam os métodos. De acordo com os comentários que expunham as opiniões dos indivíduos sobre tais práticas, foi construído o "Discurso do sujeito coletivo", o que resultou em duas vertentes: uma a favor da manobra (judô), e outra com ressalvas (jiu-jítsu). Pode-se concluir que os métodos para rápida perda de peso usados por atletas atualmente são praticados há 
décadas e seus efeitos deletérios são mencionados na literatura. Os atletas conhecem, de modo geral, os efeitos negativos dessas práticas, mas não interrompem tal hábito.

Palavras-chave: Peso Corporal. Perda de Peso. Artes Marciais.

\section{Abstract}

Judo and jiu-jitsu are two types of martial art whose techniques are based on self-defense and have a specific moral code. In martial art modalities, competitors are classified according to age and weight, in addiction to technical grades of the modality being practiced. Because of this ranking, it can be often seen that there are competitors who seek to manipulate these variables. The maneuver most frequently used and cited by athletes is body weight reduction in periods preceding championships so that they can fight shorter and lighter opponents. This study aimed to investigate weight loss methods used by judo and jiujitsu competitors and their discourse to justify their conduct. Study participants were males of various degrees of judo and jiu-jitsu. Data were collected by applying a questionnaire with specific open and closed questions on eating habits, training and competitions, as well as anthropometric measurements. The sample consisted of six jiu-jitsu athletes and four judokas, with a mean age of 23.1 years, and all in full time training for more than 12 months. Only one athlete reported that he was not familiar whatsoever with techniques for rapid weight loss; five declared they performed some type of maneuver to manipulate their weight and four athletes replied that they were familiar with the methods only. According to the comments that exemplified the opinions of the athletes about such practices, the "Collective subject discourse" was compiled, which resulted in two aspects: one in favor of the maneuver (judo) and another with reservations (jiu-jitsu). Methods for rapid weight loss used by athletes today have been a regular practice for decades and their deleterious effects are mentioned in the literature. In general, athletes have knowledge of the negative effects of these practices, but they do not break the habit.

Keywords: Body Weight. Weight Loss. Martial Arts. 


\section{Introdução}

Atualmente, as artes marciais têm possibilitado seu trânsito e disseminação por vários setores da sociedade, encontram-se constantemente associadas a um estilo de vida e orientadas por determinados valores culturais. ${ }^{1}$

O judô é uma arte marcial que deriva do jiu-jítsu, que é uma modalidade de práticas de defesa e ataque e usa apenas o corpo para defender e/ou atacar o oponente. O mestre Jigoro Kano foi o responsável por selecionar e classificar as melhores técnicas do jiu-jítsu, originando uma nova modalidade, o judô, ou "caminho gentil".?

Ojiu-jítsu, ou arte suave, é uma arte marcial com origem nos monastérios indianos e que ganhou força no Japão, sendo praticada por nobres e samurais. O princípio básico do jiu-jítsu consiste em utilizar o mínimo de força física e aproveitar a força e fraqueza do adversário. Nessa modalidade são utilizadas alavancas, pêndulos, inversão das articulações, quedas e estrangulamentos a fim de dominar o oponente. ${ }^{3}$

As duas modalidades são caracterizadas e ensinadas com finalidade esportiva e devem obedecer a normas específicas, que se enquadram aos esportes de combate. A categorização dos atletas existe para que haja homogeneização entre as disputas e é feita com base na idade e peso, além da graduação dentre a modalidade praticada. Os atletas são classificados levando-se em consideração os seguintes critérios, respectivamente: sexo, idade, graduação (cor da faixa) e peso. Ambas as modalidades consideram padrão de idade, graduação e peso semelhantes.

Em virtude dessa classificação, comumente percebem-se competidores que buscam alterar essas variáveis - atletas que alteram a idade ou competem em nível inferior de graduação ao que realmente pertencem, mas a manobra mais utilizada e mais citada em trabalhos científicos é a redução do peso corporal em períodos que antecedem os campeonatos a fim de enfrentar adversários menores e mais leves. A perda de peso intensa em curto período de tempo pode ser prejudicial a qualquer indivíduo, e para os atletas pode acarretar prejuízos, como declínio da força muscular, prejuízos na performance, queda do volume plasmático, redução na eficiência do miocárdio, diminuição do consumo máximo de oxigênio, prejuízo nos mecanismos termorreguladores, diminuição da taxa de filtração glomerular, depleção dos estoques de glicogênio e perda excessiva de eletrólitos. ${ }^{4-6}$

Os estudos envolvendo perda de peso em competidores de judô e jiu-jítsu são predominantemente quantitativos, porém, questões relativas ao coletivo podem ser mais adequadamente exploradas a partir de metodologia qualitativa, podendo expressar as percepções dos sujeitos sobre o assunto. ${ }^{7}$ Os competidores representam grupos sociais específicos, com suas crenças, valores e significados. ${ }^{8}$

O Discurso do Sujeito Coletivo (DSC) é uma técnica de tabulação e organização de dados qualitativos, desenvolvido por Lefevre \& Lefevre ${ }^{9}$ no fim da década de 1990, e tem como 
fundamento a teoria da Representação Social. O DSC é um discurso-síntese elaborado com partes de discursos de sentido semelhante, por meio de procedimentos sistemáticos e padronizados. ${ }^{10}$

Nas publicações científicas na área da saúde, as análises utilizando metodologias qualitativas ainda são escassas e pouco acessíveis aos leitores. Portanto, o presente estudo tem como objetivo principal investigar os métodos usados para perda de peso por competidores de judô e jiu-jítsu e o discurso para justificar a conduta.

\section{Metodologia}

Estudo exploratório descritivo de delineamento transversal, com abordagem quantitativa e qualitativa, realizado a partir de coleta de dados primários envolvendo competidores de judô e jiu-jítsu. Participaram do estudo apenas indivíduos do sexo masculino, com idade mínima de 16 anos, e de diversas graduações - faixa branca, azul e roxa, para competidores de jiu-jítsu; faixa amarela, marrom e preta, para competidores de judô - que tenham participado de um ou mais campeonatos da modalidade, com, no mínimo, doze meses treinando a modalidade. Foram excluídos deste trabalho os atletas pertencentes às categorias superpesado e pesadíssimo, para jiu-jítsu, e pesado e superpesado, para judô.

A coleta de dados foi realizada em 2015 e deu-se pela aplicação de um questionário desenvolvido para este trabalho pelo próprio pesquisador, uma vez que não há modelo padrão para tal avaliação. Os participantes foram entrevistados e avaliados no local de encontro, seus respectivos locais de treino. O questionário era composto por perguntas abertas e fechadas sobre alimentação, treino e competições. Além de obter dados pessoais dos participantes.

As informações de peso atual, peso habitual e estatura foram autorreferidas.

Para avaliação da composição corporal, foram aferidas as dobras cutâneas tricipital (DCT), subescapular (DCSE) e peitoral (DCP).

Para mensuração das dobras cutâneas, foi usado adipômetro clínico Sanny® com pressão constante de $9,8 \mathrm{~g} / \mathrm{mm}^{2}$. As medidas foram coletadas em duplicata, sendo todas do lado direito dos atletas, sem considerar se eram destros ou canhotos.

Ao serem entrevistados, considerou-se o quadro da pesquisa empírica, o pensamento, materializado sob forma de discurso, em que uma variável qualitativa é um produto a ser posteriormente qualificado. No entanto, esse pensamento coletivo configura-se também como uma variável quantitativa, na medida em que expressa as opiniões compartilhadas pelos indivíduos. ${ }^{11}$

As perguntas foram estrategicamente compostas, de modo a fazer com que as respostas dos indivíduos constituíssem o melhor acesso possível às representações sociais. ${ }^{12}$ Cada discurso foi observado, anotando-se o que era relevante para o trabalho, levando em conta as experiências 
em competições, fatos ocorridos com outros atletas e outros fatos pertinentes. Tudo foi usado como informação para o trabalho. De acordo com os comentários que expunham as opiniões dos indivíduos sobre tais práticas, foi construído o Discurso do Sujeito Coletivo (DSC) - proposta desenvolvida por Lefevre e Lefevre. ${ }^{9}$

As informações foram agrupadas de acordo com a ideia central, se eram contra ou a favor às manobras para perda de peso pré-competição, para cada grupo, de judô e jiu-jítsu. As opiniões compartilhadas pelos indivíduos foram demonstradas em primeira pessoa do singular, em apenas um discurso-síntese, para ilustrar o funcionamento dessas representações sociais.

Os dados coletados foram tabulados com auxílio do Microsoft $®$ Excell 2011.

Os atletas foram classificados considerando modalidade principal (judô ou jiu-jítsu), categoria de peso, idade e graduação (faixa).

A estimativa da adiposidade corporal foi obtida através da somatória das dobras cutâneas DCT, DCSE e DCP. ${ }^{13}$

As informações quantitativas foram analisadas por meio da estatística descritiva.

O trabalho respeitou todas as diretrizes da Resolução 466/2012, de Ética em Pesquisa com Seres Humanos. Todos os indivíduos que aceitaram participar da pesquisa, ou seu responsável legal quando menor de idade, assinaram o Temo de Consentimento Livre e Esclarecido.

A pesquisa está registrada sob o projeto guarda-chuva número CAAE: 50307715.7.0000.0084/2015, aprovado pelo Comitê de Ética em Pesquisa da Universidade Presbiteriana Mackenzie.

\section{Resultados}

Foram coletados dados de 11 (onze) atletas e um deles foi excluído pela classificação da categoria de peso.

A amostra do estudo foi composta por 10 (dez) atletas, sendo seis do jiu-jítsu e quatro do judô. Todos os participantes eram do sexo masculino, com idade variando entre 16 (dezesseis) e 36 (trinta e seis), com média de 23,1 anos.

Quanto à classificação por idade dos competidores, apenas dois indivíduos se encaixaram na categoria juvenil ( $\mathrm{JJ}$-2 e $\mathrm{JJ}$-4). Os demais se encaixaram na categoria adulto ou máster e apresentaram tempo maior ou igual a quinze dentro da modalidade, salvo dois competidores faixa branca de jiu-jítsu (JJ-5 e JJ-6), que têm, respectivamente, três anos e um ano de prática, o primeiro (JJ-5) com sete anos como judoca e faixa roxa. O indivíduo J-4 respondeu no questionário que já competiu quando criança, mas havia abandonado a modalidade e retornou aos treinos há pouco mais de um ano. 
Os dados de caracterização dos atletas estão dispostos na tabela 1 .

Tabela 1. Caracterização dos indivíduos participantes da pesquisa. São Paulo, 2015.

\begin{tabular}{ccccccc}
\hline Atleta & Graduação & Idade & $\begin{array}{c}\text { Tempo de } \\
\text { treino }\end{array}$ & $\begin{array}{c}\% \\
\text { Gordura }\end{array}$ & IMC & Categoria \\
\hline J-1 & Preta & 23 & 16 anos & 15,4 & 27,1 & Médio \\
\hline J-2 & Marrom & 23 & 16 anos & 7,8 & 23,1 & Ligeiro \\
\hline J-3 & Marrom & 22 & 14 anos & 8,6 & 24,5 & Leve \\
\hline J-4 & Amarela & 21 & 1 a $9 \mathrm{~m}$ & 13,7 & 21 & Meio leve \\
\hline JJ-1 & Roxa IV & 36 & 15 anos & 11,5 & 26,9 & Médio \\
\hline JJ-2 & Azul II & 17 & 4 a $6 \mathrm{~m}$ & 8,6 & 20,2 & Pena \\
\hline JJ-3 & Azul I & 32 & 1 a $9 \mathrm{~m}$ & 6,9 & 23,9 & Leve \\
\hline JJ-4 & Azul & 16 & 1 a $8 \mathrm{~m}$ & 8,6 & 20,1 & Pena \\
\hline JJ-5 & Branca IV & 19 & 3 anos & 5,9 & 22,5 & Leve \\
\hline JJ-6 & Branca II & 22 & 1 ano & 22 & 29 & Meio-pesado \\
\hline
\end{tabular}

Legenda: $\mathrm{JJ}$ = atletas do jiu-jítsu; $\mathrm{J}$ = atletas do judô.

Dos atletas que compuseram a amostra, três apresentaram IMC de sobrepeso, o estado nutricional de oito deles indica eutrofia, sendo a média de $\mathrm{IMC}=23,8$. Quanto à porcentagem de gordura corporal (GC), foram obtidos valores com classificações que variaram entre abaixo da média, na média e acima da média. Considerando os valores preconizados por Lohman, ${ }^{14}$ nenhum dos atletas apresentou níveis de GC de risco. Apresentaram valor médio de 10,9\% de gordura corporal.

A classificação do percentual de GC dos atletas está disposta na tabela 2. 
Tabela 2. Classificação do percentual de gordura corporal dos indivíduos participantes da pesquisa, São Paulo, 2015.

\begin{tabular}{ccc}
\hline Classificação & \% Gordura corporal & № de competidores \\
\hline Alto risco $^{1}$ & $\geq 25 \%$ & 0 \\
\hline Acima da média & $17-24 \%$ & 1 \\
\hline Na média & $14,5-16 \%$ & 1 \\
\hline Abaixo da média & $6-14 \%$ & 8 \\
\hline Alto risco & $\leq 5 \%$ & 0 \\
\hline
\end{tabular}

Fonte: Lohman. ${ }^{13}$

Legenda: ${ }^{1}=$ alto risco para doenças e desordens associadas à obesidade. ${ }^{2}=$ alto risco para doenças e desordens associadas à desnutrição.

Todos os participantes relataram ter tempo total de treino superior a um ano. No tempo total de treino não foram desconsiderados períodos em que os treinos foram interrompidos por quaisquer motivos.

Para os atletas do judô, a graduação foi diretamente proporcional ao tempo total de treino, ou seja, quanto mais extensa a vida esportiva do atleta, mais graduado ele era. Quanto aos atletas do jiu-jítsu, o tempo total de treino não influenciou totalmente a amostra, pois houve atletas com menos tempo de treino quando comparado a outros e eram mais graduados.

Do total da amostra, quatro mencionaram praticar outra modalidade esportiva, sendo citadas: musculação, outra modalidade de luta e treinos aeróbicos funcionais. Os atletas justificaram afirmando que esses treinos adicionais aperfeiçoavam o desempenho nos treinos da modalidade principal, além de ser um hobby.

De toda a amostra, apenas um judoca relatou não ter qualquer familiaridade com as técnicas para rápida perda de peso referidas no questionário.

Ao ser questionados sobre a necessidade de perder peso antes de uma luta, cinco atletas disseram já ter precisado perder peso para um combate, e desses, quatro afirmaram já ter recorrido às práticas para rápida perda de peso citadas no formulário de perguntas.

Os métodos apresentados pelos atletas para perda de pesos estão no quadro abaixo (quadro 1). 
Quadro 1. Métodos para perda de peso citados pelos atletas, São Paulo, 2015.

\begin{tabular}{|c|c|c|c|c|}
\hline \multicolumn{5}{|c|}{ MÉTODOS PARA RÁPIDA PERDA DE PESO } \\
\hline $\begin{array}{c}\text { Uso de roupas plásticas/ } \\
\text { moletons/outros }\end{array}$ & $\begin{array}{c}<\text { ingestão de } \\
\text { alimentos }\end{array}$ & $\begin{array}{c}<\text { ingestão } \\
\text { de líquidos }\end{array}$ & $\begin{array}{c}>\text { tempo de } \\
\text { treinos aeróbicos }\end{array}$ & Sauna \\
\hline Citado 3x & Citado 4x & Citado 3x & Citado 4x & Citado 3x \\
\hline
\end{tabular}

Os atletas que relataram realizar manobras para perda de peso antes das lutas foram questionados sobre os responsáveis pela orientação/sugestão dos métodos adotados, e as respostas foram: "outros atletas (companheiros de treino)" e "os métodos foram adotados por conta própria".

Tratando-se de campeonatos e a necessidade de perder peso em período pré-competitivo, três atletas do jiu-jítsu e um do judô afirmaram que competem na categoria de peso à qual pertence seu peso atual/habitual. Mas que esse tipo de prática era bastante comum nas equipes, embora a considerem prejudicial. Quando foi perguntada aos atletas sua opinião sobre a perda rápida de peso antes de uma luta, os discursos foram sempre relacionados ao rendimento imediato.

Ao mesmo tempo que eram relatados os pontos negativos das práticas citadas no questionário, os atletas as consideravam normais ou comuns, seja por muitos realizarem tais manobras, seja por saberem, pelas mídias, que atletas de elite também procediam da mesma forma.

Durante o questionamento, foi tomada nota dos comentários feitos, sobre o assunto, pelos atletas.

No quadro 2, pode-se conferir o discurso dos atletas sobre os métodos para perda de peso, pela metodologia do Discurso do Sujeito Coletivo. ${ }^{9}$ 
Quadro 2. Discursos-síntese dos atletas quanto aos métodos para perda de peso, São Paulo, 2015 .

\begin{tabular}{|c|c|}
\hline ATLETAS DO JIU-JÍTSU & ATLETAS DO JUDÔ \\
\hline $\begin{array}{l}\text { - Discurso contra as manobras } \\
\text { "Ao diminuir a ingestão de alimentos } \\
\text { nos privamos dos nutrientes que nos dão } \\
\text { força e gás para um combate. Desidratar } \\
\text { não é emagrecer." "Desidratar não é } \\
\text { emagrecer. O cara só perde peso, né?” } \\
\text { "Considero prejudicial, pois desgasta o } \\
\text { atleta e diminui o rendimento. Tanto } \\
\text { ficar muito tempo sem comer, quanto } \\
\text { desidratar demais pode prejudicar um } \\
\text { dia de campeonato porque fazemos pelo } \\
\text { menos cinco lutas no mesmo dia." } \\
\text { - Discurso justificando as manobras } \\
\text { "Bem não faz, mas não acho que } \\
\text { prejudique muito porque não duram muito } \\
\text { tempo.” "Desidratar tanto pode diminuir o } \\
\text { rendimento, mas são coisas normais, todo } \\
\text { mundo faz." “Tem coisas que são saudáveis, } \\
\text { como comer menos. Tem também as que } \\
\text { podem prejudicar como desidratar demais, } \\
\text { que pode causar queda no desempenho, } \\
\text { mas nos campeonatos a gente sempre vê } \\
\text { um pessoal correndo porque ainda precisa } \\
\text { perder peso.” }\end{array}$ & $\begin{array}{l}\text { - Discurso a favor das manobras } \\
\text { “Todo mundo faz, é normal.” E “tem } \\
\text { coisas que podemos fazer que são } \\
\text { saudáveis, outras são prejudiciais.” Essas } \\
\text { "são técnicas prejudiciais, mas sempre } \\
\text { tenho que perder peso antes de uma luta } \\
\text { e preciso fazer alguma coisa.” E “é normal } \\
\text { a gente ver no dia da luta um pessoal que } \\
\text { ainda precisa perder peso correndo em } \\
\text { volta dos tatames, por exemplo"; mesmo } \\
\text { considerando "prejudicial, mas é normal } \\
\text { fazer.” E “já fiz tudo isso que está aqui } \\
\text { (opções do formulário), pode prejudicar, } \\
\text { mas é normal.” }\end{array}$ \\
\hline
\end{tabular}


De toda amostra, apenas um atleta citou já ter tido contato com profissional de nutrição. Esse mesmo atleta afirmou nunca ter recorrido a nenhum dos métodos para perda de peso citados no questionário aplicado na coleta de dados deste trabalho.

Os atletas do jiu-jítsu pertenciam todos à mesma equipe e eram treinados pelo mesmo mestre e pelo mesmo professor. Os judocas realizavam alguns treinos juntos, mas pertenciam a equipes diferentes.

\section{Discussão}

As modalidades de luta apresentam como critérios para classificar os atletas o nível técnico (graduação/faixa), a idade e o peso. Quanto à idade, é bastante comum que a prática se inicie na infância ou adolescência. Neste estudo, apenas dois indivíduos pertenciam à categoria juvenil (até 17 anos), mas pelo tempo total de treino dos atletas hoje pertencentes às categorias adulto e máster, nota-se que quase todos iniciaram na infância ou adolescência. Os atletas que ainda estão na fase da infância ou adolescência devem ser colocados em um grupo especial de atenção. Sabese que durante essas fases cruciais de crescimento e desenvolvimento humanohá uma demanda nutricional específica que, se não for suprida, pode acarretar danos com reflexos em longo prazo. Além da pressão que esses indivíduos podem sofrer por conta do esporte, deve-se levar em conta a existência de diversos fatores que interferem no consumo adequado de alimentos. ${ }^{15}$

Os dois atletas juvenis que participaram deste trabalho, mesmo conhecendo as manobras, relataram nunca ter realizado nenhuma para perder peso. No entanto, no trabalho de Almeida et al., ${ }^{16}$ que estudou os hábitos de hidratação em 36 adolescentes judocas brasileiros, metade da amostra afirmou já ter precisado perder peso antes de um campeonato. Para isso, $48 \%$ aumentaram o nível de exercícios físicos, 36\% fizeram algum tipo de restrição alimentar, $8 \%$ limitaram a ingestão de líquidos e $8 \%$ usaram roupas especiais para treinar. Os métodos usados pelos adolescentes judocas são os mesmos apontados por este estudo e pela maioria dos aqui citados, confirmando o quanto esses métodos são comuns.

Mais importante que o peso corporal total, a composição corporal deveria ser avaliada e levada em conta na classificação dos atletas. Os relatos de que atletas acabaram indo a óbito por adotarem práticas prejudiciais para perda de peso são conhecidos e apontados não apenas em estudos científicos, mas também em matérias de revistas populares e outras mídias. ${ }^{17,18} \mathrm{O}$ modelo clássico de divisão da composição corporal divide o corpo em duas partes: uma consiste na gordura corporal, e os demais tecidos são agrupados e denominados massa magra ou massa isenta de gordura. Embora os valores sejam variados, o porcentual de gordura corporal ideal todos seguem bem próximo aos preconizados por Lohman. ${ }^{13}$ Levando em consideração tal classificação, oito dos atletas apresentaram porcentual de gordura corporal abaixo da média (entre 6\% e 14\%). Valores muito 
baixos desse componente podem indicar alto risco de doenças e desordens associadas à desnutrição. Os lipídeos são essenciais ao organismo humano, pois são fundamentais no desempenho de funções básicas, como a formação de membranas celulares, fornecimento energético, transporte e armazenamento de vitaminas lipossolúveis (A, D, E e K), funcionamento do sistema nervoso, atividade do sistema reprodutor e produção dos hormônios esteroides. Apesar de não ser via de regra, os indivíduos com baixa porcentagem de gordura corporal, frequentemente, apresentam desordens alimentares. ${ }^{19}$

A fim de se encaixar em disputas que possam lhes proporcionar determinada vantagem, por vezes os atletas tentam alterar as variáveis que os classificam, sendo as alterações bruscas no peso corporal o principal manejo realizado. ${ }^{20}$ Este segundo ponto citado e seus efeitos fisiológicos são os principais motivadores para a efetivação deste estudo.

De acordo com o levantamento bibliográfico realizado por Hirschbruch \& Carvalho, ${ }^{20}$ os métodos mais comumente praticados por atletas de combate para perda de peso são a restrição de líquidos e alimentos, realização de treinos aeróbicos trajando roupas plásticas ou emborrachadas e sauna seca ou úmida. Essas práticas podem começar semanas antes de uma luta, mas sabe-se que chegam a ser praticadas até algumas horas antes da pesagem.

Essa informação corrobora o discurso de alguns dos atletas participantes deste estudo, que chegaram a relatar o seguinte: "(...) nos campeonatos a gente sempre vê um pessoal correndo porque ainda precisa perder peso" e "é normal a gente ver no dia da luta um pessoal que ainda precisa perder peso correndo em volta dos tatames, por exemplo." Durante as entrevistas, mesmo os atletas que afirmaram nunca ter realizado qualquer manobra para perder peso antes de uma luta comentaram que todas aquelas práticas eram normais, ou seja, são usualmente realizadas e os atletas dessas modalidades já estão habituados a elas.

O discurso dos competidores permite a confirmação de que os atletas buscam maneiras de perder peso em período de tempo extremamente curto, até mesmo no dia da competição. A perda de peso em tempo menor que uma semana é a mais perigosa, pois o peso perdido nesse tempo é basicamente de perda hídrica, o que representa um perigo para o organismo, pois interfere nos mecanismos de termorregulação e na capacidade de sudorese, que acaba prejudicando a força e resistência do atleta. ${ }^{21}$

Sabe-se que existem diversas maneiras que visam à perda de peso que podem ser usadas por esses atletas. Essas estratégias podem ser classificadas em três grupos: os de redução rápida de peso, os de redução gradual de peso e ainda os considerados métodos patogênicos. ${ }^{20}$

As práticas que apareceram com maior frequência nos trabalhos já publicados serviram como base para a montagem do questionário. Além dos métodos mais comumente presentes entre os atletas, também é possível citar outros achados que podem ser classificados como métodos 
patogênicos. Esses métodos também resultam na perda de peso em curto espaço de tempo, mas são totalmente condenáveis, pois comprometem o atleta física e mentalmente. ${ }^{20,22}$

Não houve relatos da adoção do uso de laxantes, diuréticos, moderadores de apetite ou indução do vômito pelos competidores. Esses métodos são considerados patogênicos por causarem efeitos negativos no desempenho do atleta em decorrência de alterações físicas e/ou mentais, além de induzir a transtornos alimentares, como anorexia e bulimia, principalmente no público mais predisposto, o de atletas do sexo feminino. ${ }^{20}$

Apesar da ocorrência dos distúrbios alimentares ser predominante em atletas do sexo feminino, eles também ocorrem no sexo masculino e são igualmente preocupantes. Os casos de distúrbios alimentares, especialmente a bulimia, em homens atletas ocorrem principalmente nas modalidades em que o controle do peso é muito rígido e supervalorizado. ${ }^{23}$ Em um estudo que investigou as condutas alimentares e a distorção da autoimagem com 101 judocas, ficou evidente a presença de distúrbios de atitudes alimentares em 30,7\% da amostra estudada, 41,9\% desses sendo atletas do sexo masculino. ${ }^{24}$

Em estudo que visou investigar os métodos para perdas bruscas de peso praticados por lutadores de jiu-jítsu, os indivíduos afirmaram recorrer a diversos artifícios, e entre os citados foram encontradas táticas como: uso de diuréticos (18,1\%), de laxantes (9\%), de pílulas dietéticas (9\%), provocação de vômitos (4,5\%). Os métodos patogênicos, quando comparados com os de redução rápida de peso, são pouco usuais, mas ainda são colocados em prática. ${ }^{25}$ De acordo com o Comitê Olímpico Internacional (COI) e a Agência Mundial Antidoping, o uso de diuréticos é caracterizado como doping e infringe os códigos éticos e disciplinares e pode acarretar em punições aos atletas e suas respectivas comissões técnicas. ${ }^{26}$

Além de acarretar em punição, o uso de diuréticos pode levar o atleta a desencadear hipocalemia, ou a queda dos níveis de potássio no sangue. Essa alteração pode interferir no funcionamento do mecanismo da bomba de sódio-potássio, comprometendo a diferença de carga elétrica que deve ser mantida entre o meio intra e extracelular. Essa alteração causa perda do equilíbrio osmótico e compromete a atividade de células musculares e nervosas que dependem desse mecanismo para que haja penetração de aminoácidos e açúcares. ${ }^{27}$

$\mathrm{Na}$ amostra que compôs o estudo, nove atletas disseram ter alguma familiaridade com as técnicas, mesmo que nunca tenham praticado; metade dos indivíduos afirmou já ter precisado perder peso antes de uma luta, e desses, quatro relataram ter recorrido a algum método para perder peso em curto período de tempo. Ao justificar sua opinião sobre os métodos para perder peso citados no questionário, os atletas do jiu-jítsu apresentaram mais ideias negativas e de repreensão a essas práticas. Os judocas, por sua vez, também tinham a consciência de que tais métodos eram prejudiciais, mas que eram normais (durante a análise de dados, a resposta "normal" foi entendida 
como "comum"). Além disso, citaram como fonte de orientação outros atletas/outros competidores - não foi perguntado se esses outros atletas pertenciam ou não à mesma equipe.

As representações sociais são esquemas sociocognitivos que as pessoas utilizam para emitir, no seu cotidiano, juízos ou opiniões. Estes resultados ilustram que a pesquisa com o DSC pode gerar um painel de opiniões coletivas em que uma mesma opinião adquire matizes distintos, na medida em que é gerada por atores sociais distintos (no caso, judocas se posicionando a favor das manobras e lutadores de jiu-jítsu apenas justificando a utilização); que resultados qualitativos (os discursos) e quantitativos podem se articular. $^{12}$

Como discute Leferre, Lefevre \& Marques, ${ }^{11}$

a presença mais significativa do material empírico, aliada ao entendimento do pensamento das coletividades como referente, permite o diálogo do momento descritivo com o momento interpretativo neste tipo de pesquisa, podendo, assim, como nova possibilidade que aponta para o incerto e para o inesperado, contribuir para um entendimento renovado da natureza e do funcionamento das representações sociais como realidades complexas.

Sugere-se que a ideia semelhante dos atletas, seja positiva ou negativa, deve-se à influência do mestre da equipe, que é responsável por destacar pontos fortes e fracos dos atletas e exigir mudanças de postura em diversos aspectos de suas vidas, principalmente em períodos de competição. Dentro da equipe, além de liderar os alunos e auxiliar no aperfeiçoamento técnico contínuo, o professor serve de espelho para os seus alunos e carrega a responsabilidade de despertar sempre o melhor de cada atleta que venha ao seu contato.

Em estudo sobre práticas para redução de peso em judocas, ${ }^{5}$ foi questionado aos participantes qual a principal fonte de orientação à manipulação da massa corporal. Os principais responsáveis por tal orientação eram o preparador físico (78\%) e o treinador (57\%), seguidos de revistas (40\%) e amigos (37\%). A partir dos resultados encontrados neste trabalho, notamos a importante influência exercida pelo mestre das equipes sobre os atletas, evidenciada não apenas no judô e jiu-jítsu, mas também em outras artes marciais.

Em estudo feito com atletas de karatê shotokan, modalidade que dispensa classificação por peso, não foram encontradas práticas visando à redução ponderal nem a aplicação de substâncias ergogênicas ou medicamentos que possam influenciar no desempenho do atleta. Os autores sugerem que isso se dê a partir da filosofia da modalidade, cujos estímulos através do controle do corpo e da mente sejam os maiores desafios para os indivíduos. ${ }^{20,28}$

A filosofia do jiu-jítsu vai muito além da prática das técnicas, a disciplina e o equilíbrio. Em suma, a adoção de bons hábitos alimentares, cuidados com o corpo, manter-se afastado do álcool e outras drogas e próximo da família e amigos são atitudes que devem ser ensinadas pelos professores 
e praticadas pelos alunos. Essas condutas refletem não somente no desempenho do atleta, mas também na sua vida de modo geral. ${ }^{29}$

\section{Conclusão}

Para que o pensamento coletivo pudesse se autoexpressar por meio desta pesquisa empírica, fezse necessária a constituição de um sujeito portador do discurso coletivo: um sujeito coletivo. Assim, analisando-se o DSC, pôde-se constatar que a familiaridade com os métodos para rápida perda de peso é quase unânime entre competidores de judô e jiu-jítsu, mas a prática dos métodos não foi tão frequente nos indivíduos deste estudo. As manobras mais citadas foram as que diminuem a hidratação corporal por meio da sudorese e restrição hídrica, além da limitação energética da dieta.

A composição corporal dos atletas indicou que a maioria dos indivíduos apresenta porcentagem de gordura corporal abaixo da média, o que já era esperado, visto que se tratou de um estudo com indivíduos com alta frequência e intensidade de atividade física.

A intervenção nutricional em atletas é fundamental para que eles sejam orientados corretamente sobre a forma mais adequada de manter o peso ideal, uma vez que esta variável é determinante em competições. Ademais, os treinadores também devem ser orientados, pois são os que mais exercem influência sobre o comportamento esportivo desses indivíduos.

Apesar de saberem que essas práticas são prejudiciais, tais manobras ainda são muito utilizadas, o que se dá pela falta de instrução e esclarecimento sobre os danos que esses métodos acarretam à saúde em longo prazo e sobre a maneira correta de controlar o peso corporal.

\section{Colaboradores}

Souza CKS e Abreu ES participaram de todas as etapas, desde a concepção do estudo até a revisão da versão final do artigo.

Conflito de Interesses: Os autores declaram não haver conflito de interesses.

\section{Referências}

1. Gonçalves AVL, Santos da Silva MR. Artes marciais e lutas: uma análise da produção de saberes no campo discursivo da educação física brasileira. Rev Bras Ciênc Esporte 2013; 35:657-71.

2. Embaixada do Japão no Brasil. Da antiga tradição aos esportes modernos. Revista Nippon e Niponic 2012. [acesso em: 13 jan. 2016]. Disponível em: http://www.br.emb-japan.go.jp/cultura/ artesmarciais.html 
3. Virgílio S. Conde Koma: o invencível yondan da história. Campinas: Átomo; 2002.

4. Artioli GG, Scagliusi FB, Polacow VO, Gualano B, Lancha Junior AH. Magnitude e métodos de perda rápida de peso em judocas de elite. Rev Nutr. 2007; 20(3):307-15.

5. Fabrini SP, Brito CJ, Mendes EL, Sabarense CM, Marins JCB, Franchini E. Práticas de redução de massa corporal em judocas nos períodos pré-competitivos. Rev Bras Educ Fís Esporte 2010; 24(2):165-77.

6. Hall C, Lane A. Effects of rapid weight loss on mood and performance among amateur boxers. $\mathrm{Br}$ J Sports Med. 2001; 35:390-5.

7. Rocha EM, Alves M. Metodologia qualitativa. In: Bicas HEA, Rodrigues MLV, editores. Metodologia científica. Rio de Janeiro: Cultura Médica; 2008. p. 337-40.

8. Minayo MCS. O Desafio do conhecimento. Pesquisa qualitativa em saúde. 8 a ed. São Paulo: Hucitec; 2004.

9. Lefevre F, Lefevre AMC. O discurso do sujeito coletivo: um enfoque em pesquisa qualitativa (Desdobramentos). Caxias do Sul: EDUSCS; 2003.

10. Lefevre F, Lefevre AMC. Pesquisa qualitativa levada a sério [Internet]. São Paulo: USP; 2003. [acesso em: set. 2016]. Disponível em: http://www.fsp.usp. br/ flefevre/Discurso_o_que_e.htm

11. Lefevre F, Lefevre AMC, Marques MCC. Discurso do sujeito coletivo, complexidade e autoorganização. Ciênc Saúde Coletiva 2009; 14(4):1193-1204.

12. Lefevre F, Lefevre AMC. Pesquisa de representação social. Brasília: Liberlivro; 2010.

13. Jackson AS, Pollock ML. Generalized equations for predicting body density of men. Br J Nutr. 1978; 40:497-504.

14. Lohman TG. Advances in body composition assessment Champaign, IL: Human Kinetics Publishers; 1992.

15. Perron M, Endres J. Knowledge, attitudes, and dietary practices of female athletes. J Am Diet Assoc. 1985; 85:573-76.

16. Almeida EC, Cavalieri MC, Hirschbruch MD, Pádua Cintra I, Fisberg M. Hábitos de hidratação em adolescentes praticantes de judô. Pediatr Mod. 2005; 41(6):291-300.

17. Ransone J, Hughes B. Body-weight fluctuation in collegiate wrestlers: implications of the National Collegiate Athletic Association Weight-Certification Program. J Athl Train. 2004; 39:162-5.

18. Correia D. Atletas do UFC perdem até $16 \mathrm{~kg}$ para 'enganar' a balança. Veja [Internet]. 8 ago. 2011. [acesso em: 13 jan. 2016]. Disponível em: http://veja.abril.com.br/noticia/esporte/lutadores-do-ufcperdem-ate-16-kgs-para-enganar-a-balanca

19. Cezar C. Alguns aspectos básicos para uma proposta de taxionomia no estudo da composição corporal, com pressupostos em cineantropometria. Rev Bras Med Esporte 2000; 6(5):188-93.

20. Hirschbruch MD, Carcalho JR. Nutrição esportiva: uma visão prática. São Paulo: Manole; 2002.

21. Quintão DF. Estratégias rápidas para perda ponderal, composição da refeição pré-treino e nível de desidratação em atletas de jiu-jitsu de Ipatinga-MG. Rev Brasil Nutr Esportiva 2013; 7(41):269-78. 
22. Foss ML, Keteyian SJ. Bases fisiológicas do exercício e do esporte. $\sigma^{a}$ ed. Rio de Janeiro: Guanabara Koogan; 2000.

23. Mellin P, Araújo AM. Transtornos alimentares em homens: um desafio diagnóstico. Rev Bras Psiquiatr. 2002; 24(Supl. III):73-6.

24. Vieira J, Oliveira L, Vieira L, Vissoci J, Hoshino E, Fernandes S. Distúrbios de atitudes alimentares e sua relação com a distorção da auto-imagem corporal em atletas de judô do Estado do Paraná. R Educação Física/UEM 2006; 17(2):177-184.

25. Ribas MR, Stainsack JM, Shuluga Filho J, Tambui PB, Zyla AL, Zonatto H A, et al. Técnicas bruscas para perda de peso em lutadores de Jiu-Jitsu. Revista UNIANDRADE 2015; 16(1):15-21.

26. Carvalho T, Rodrigues T, Meyer F, Lancha Jr AH, Rose EH. Modificações dietéticas, reposição hídrica, suplementos alimentares e drogas: comprovação de ação ergogênica e potenciais riscos para a saúde. Rev Bras Med Esporte 2003; 9:43-56.

27. Amabis JM, Martho GR. Fundamentos da biologia moderna. $3^{\text {a }}$ ed. São Paulo: Moderna; 2003.

28. Rossi L, Figueira RT, Fabri A, Segli J, Tirapegui J. Avaliação antropométrica e das razões para prática de artes marciais. Rev Nutr Brasil 2007; 6(2):100-4.

29. Código de conduta dos instrutores [Internet]. Gracie Barra [acesso em: 13 jan. 2016]. Disponível em: http://www.graciebarra.com/br/codigo-de-conduta/

Recebido: 04/4/2016

Revisado: $21 / 9 / 2016$

Aceito: 01/11/2016 